\title{
The effects of hyperglycaemia on changes during reperfusion following focal cerebral ischaemia in the
} cat

\author{
GS VENABLES, ${ }^{*}$ SUSIE A MILLER, $†$ G GIBSON, $†$ JA HARDY $\ddagger$ AJ STRONG $\dagger$ \\ From the Departments of Neurology, ${ }^{*}$ and Surgery (Neurosurgery) $\dagger(S A M, G G, A J S)$ and the Medical \\ Research Council Neuroendocrinology Unit, $\ddagger$ University of Newcastle upon Tyne, Newcastle upon Tyne, UK
}

SUMMARY The effects of isosmolar loads of glucose and saline after onset of focal cerebral ischaemia (middle cerebral artery occlusion) were compared in cats. In cats given saline cerebral blood flow (CBF) fell and then rose slightly on the marginal gyrus (infarct penumbra). There was a sustained fall in CBF on the suprasylvian and ectosylvian gyri (infarct core). Reperfusion restored blood flow to preocclusion levels with no overall postischaemic hypoperfusion. Below ischaemic flows of $14 \mathrm{ml} / 100 \mathrm{~g} / \mathrm{min}$ brain specific gravity was reduced in a smaller proportion of gyri by contrast with non reperfused cortex, suggesting that in some gyri resolution of cerebral oedema had taken place. GABA uptake was normal in the infarct core, but was reduced within the ischaemic penumbra. In animals given glucose after occlusion, CBF fell on the marginal gyrus during reperfusion. The degree of resolution of cerebral oedema was less than in saline infused cats. GABA uptake showed a pattern of abnormality similar to that seen in saline infused cats, except that uptake values were lower in the infarct core. Pial surface potassium activity remained elevated in the penumbra following reperfusion in glucose infused cats, but returned to normal in saline infused cats. Implications for the management of cerebral ischaemia in man are discussed.

Restoration of the blood supply to ischaemic brain following occlusive stroke does not necessarily imply functional viability. In experimental focal cerebral ischaemia, the distribution of which in the cat we have previously described, ${ }^{2}$ blood supply is restored in the postischaemic period to a degree which is related to the duration and severity of the ischaemia. ${ }^{3}$ Some of the biochemical mechanisms thought to operate during ischaemia and reperfusion have recently been reviewed, and include the appearance of free radicals in association with reduced or restored oxygen supply, and the accumulation of lactic acid. ${ }^{4}$ In man mild degrees of hyperglycaemia may be seen after the onset of stroke and this study was designed to examine whether hyperglycaemia of this pattern, by increasing lactic acid concentration in the brain, might worsen the effects of the ischaemia, in particular with respect to $\mathrm{CBF}$,

Address for reprint requests: AJ Strong FRCS, Regional Neurological Centre, Newcastle General Hospital, Newcastle upon Tyne, NE1 4LP.

Received 6 April 1984 and in revised form 20 October 1984. Accepted 27 October 1984 pial surface potassium activity, cerebral water content and in vitro neurotransmitter uptake. Core and penumbral territories were examined separately in the expectation that any adverse effects of hyperglycaemia would be more clearly recognisable in an incompletely affected than in a severely affected area. We define the penumbra as a cortical territory subject to reduction of blood flow and suppression of electrophysiological function but in which extracellular potassium ion homeostasis is largely preserved.

\section{Methods}

Anaesthetic, operative and experimental techniques have been described previously. ${ }^{2}$ Fasting adult mongrel cats (weight range $2 \cdot 1-4 \cdot 2 \mathrm{~kg}$ ) were anaesthetised with halothane and a mixture of oxygen and nitrous oxide, and anaesthesia was then maintained with a single intravenous dose of alpha chloralose $(60 \mathrm{mg} / \mathrm{kg}$ ) supplemented by inhaled halothane $(<0.5 \%)$ if mean arterial blood pressure rose above $120 \mathrm{mmHg}$. Animals were paralysed with gallamine triethiodide and ventilated to maintain $\mathrm{PaCO}_{2}$ at 28-32 mmHg. Arterial $\mathrm{pH}, \mathrm{pO}_{2}$ and $\mathrm{pCO}_{2}$ plasma glucose and serum osmolality were measured intermittently. 
The right middle cerebral artery was approached by transorbital dissection and, after baseline measurements had been made, was occluded using a miniature Scoville clip. The left marginal and right marginal, suprasylvian and ectosylvian gyri were exposed: recording electrodes were positioned and the brain covered with a pool of warmed mineral oil.

CBF was measured by hydrogen clearance, flows being analysed by the two minute initial slope method..$^{5}$ Pial surface potassium activity was measured using valinomycin membrane electrodes with an adjacent mechanically coupled reference barrel, the combined unit being suspended from a high impedance differential amplifier. Cortical specific gravity was measured by microgravimetry and used as an index of brain water content. In vitro synaptosomal GABA uptake was measured using ${ }^{3} \mathrm{H}$ or ${ }^{14} \mathrm{C} \mathrm{GABA}$ and was expressed as $\mathrm{nmol} / \mathrm{g}$ wet weight $/ \mathrm{min}^{2}$

After occlusion cats were given either $2 \mathrm{~N}$ saline (Group $1, n=10$ ) or $10 \%$ D-glucose (Group $2, n=10$ ) at 20 $\mathrm{ml} / \mathrm{hr}$. Group 1 and 2 experiments were carried out for the most part in alternation. The clip was removed after 2 hours and the infusion stopped; after reperfusion for 1 hour ribbons of cortex were excised from relevant gyri for microgravimetry and neurochemistry.

As conventional indices of mean value and dispersal the mean \pm SEM is given in the text and tables; however, since the data was not always normally distributed, statistical analysis was performed using the non parametric two tailed Wilcoxon signed rank test or Mann Whitney $U$ test except where otherwise stated.

\section{Results}

\section{Physiological variables (table 1)}

Mean values for arterial blood pressure, $\mathrm{pH}, \mathrm{pO} 2$ and $\mathrm{pCO} 2$ are shown in table 1 . The two groups were comparable and variables did not change significantly during each experiment.

\section{Plasma glucose and osmolality (table 1)}

Plasma glucose remained constant throughout in Group 1; in Group 2 preocclusion values were similar to those in Group 1. There was a rise in glucose during occlusion which was sustained during reperfusion ( $p=0.001$ compared with preocclusion, Students $t$ test; $p=0.01$ compared with Group 1). There was no significant change in serum osmolality during any experiment and the two groups were statistically similar.

\section{Cerebral blood flow (table 2)}

Preocclusion whole hemisphere $\mathrm{CBF}$ was $33.2 \pm$ $1.38 \mathrm{ml} / 100 \mathrm{~g} / \mathrm{min}$ in Group 1 and $37.3 \pm 1.38 \mathrm{ml} /$ $100 \mathrm{~g} / \mathrm{min}$ in Group 2. Flow on the marginal gyrus (MG) fell in Group 1 compared with preocclusion CBF $(p=0.01)$ and did not change during occlusion, but was restored to preocclusion values during reperfusion. In Group 2 the fall in CBF was less though still significant $(p=0.01)$ and $C B F$ was restored to preocclusion values at the start of reperfusion, during which there was a slight fall in $\mathrm{CBF}$ ( $\mathrm{p}$ $<0.05$, comparing terminal with initial reperfusion $\mathrm{CBF}$ ). On the suprasylvian gyrus (SG) there was a significant fall in $\mathrm{CBF}$ in both groups compared with preocclusion values' $(p<0.01) ; C B F$ remained unchanged during occlusion and returned to preocclusion values during reperfusion. On the ectosylvian gyrus (EG) both groups showed similar changes in CBF with a fall during occlusion ( $p=0.01$ com-

Table 1 Systemic arterial blood pressure and blood gases, plasma glucose and osmolality (mean $\pm S E M$ ).

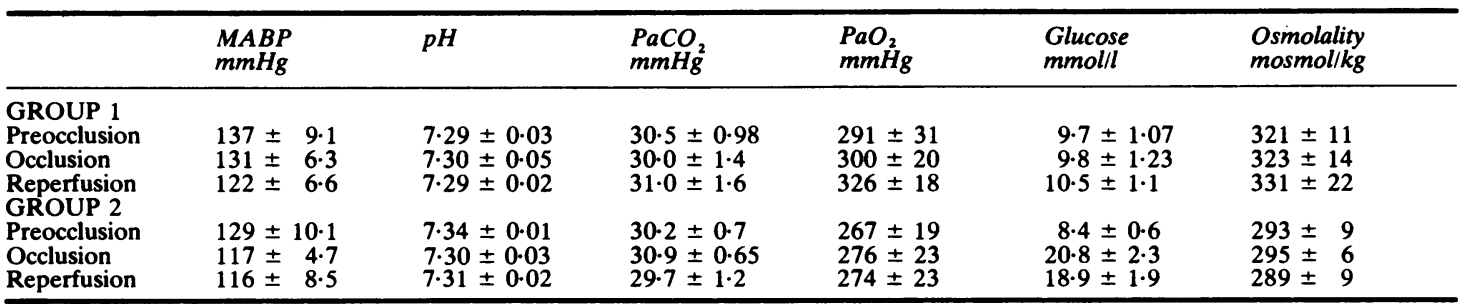

Table 2 Regional cerebral blood flow $\mathrm{ml} / 100 \mathrm{~g} / \mathrm{min}(\mathrm{mean} \pm S E M$ )

\begin{tabular}{|c|c|c|c|c|c|c|}
\hline \multirow[t]{2}{*}{ Group } & \multicolumn{2}{|c|}{ Marginal gyrus } & \multicolumn{2}{|c|}{ Suprasylvian gyrus } & \multicolumn{2}{|c|}{ Ectosylvian gyrus } \\
\hline & 1 & 2 & 1 & 2 & 1 & 2 \\
\hline $\begin{array}{l}\text { Preocclusion } \\
\text { Occlusion }\end{array}$ & $34 \cdot 5 \pm 4 \cdot 1$ & $34 \cdot 2 \pm 5 \cdot 5$ & $28 \cdot 0 \pm 2.0$ & $36.8 \pm 7 \cdot 8$ & $38 \cdot 0 \pm 3.5$ & $39.3 \pm 2.9$ \\
\hline $\begin{array}{l}2 \text { minute } \\
\text { terminal } \\
\text { mean }\end{array}$ & $\begin{array}{l}18.5 \pm 2.0 \\
20.7 \pm 2.4 \\
20.2 \pm 1.9\end{array}$ & $\begin{array}{l}25 \cdot 3 \pm 5 \cdot 0 \\
27 \cdot 5 \pm 3 \cdot 6 \\
27 \cdot 7 \pm 4 \cdot 4\end{array}$ & $\begin{array}{r}10.9 \pm 1.3 \\
8.9 \pm 1.1 \\
9.9 \pm 1.1\end{array}$ & $\begin{array}{l}12.6 \pm 1.5 \\
10.7 \pm 1.4 \\
11.5 \pm 1.4\end{array}$ & $\begin{array}{r}11.5 \pm 1.2 \\
8.6 \pm 1.2 \\
9.6 \pm 1.3\end{array}$ & $\begin{array}{l}11.6 \pm 1.8 \\
11.0 \pm 2.4 \\
10.9 \pm 1.9\end{array}$ \\
\hline
\end{tabular}


pared with preocclusion $\mathrm{CBF}$ ) and restoration to preocclusion values during reperfusion. This resembled the situation previously reported in animals subject to occlusion alone. The differences in mean occlusion CBF between MG-SG and MG-EG were significant in both groups $(p<0 \cdot 01)$. In Group 1 there was no difference between gyri during reperfusion, but in Group $2 \mathrm{CBF}$ was consistently higher on EG than SG $(p<0.02)$. Whole hemisphere CBF and cerebral vascular resistance were similar in each group during reperfusion.

\section{Electrocorticogram (ECoG)}

The ECoG was measured on MG. Similar changes were seen in both groups with a greater than $75 \%$ reduction in the amplitude of the time compressed voltage envelope during occlusion and no recovery during reperfusion.

\section{Cortical specific gravity (table 3)}

A significant reduction in cortical specific gravity occurred in Group 1 in EG $(p<0.02)$, and in Group 2 in both SG and EG $(p<0 \cdot 01)$, where there were also significant differences between MG and SG ( $p$ $<0.02)$ and between MG and EG ( $<<0.01)$. The reduction in specific gravity on homologous gyri was similar in Groups 1 and 2. In previous experiments in which animals were not reperfused we have shown that cortical specific gravity only falls when blood flow falls below $14 \mathrm{ml} / 100 \mathrm{~g} / \mathrm{min}^{2}$ In the present experiments there was no fall in specific gravity when occlusion flows lay above $14 \mathrm{ml} / 100 \mathrm{~g} / \mathrm{min}$. Below $14 \mathrm{ml} / 100 \mathrm{~g} / \mathrm{min}$ there was a substantially wider range of values for the fall in specific gravity which was of bimodal distribution and independent of infusate (fig 1a), compared with the normal distribution in non-reperfused cats ${ }^{2}$ (fig 1b). The variance of the reduction in specific gravity was significantly greater in reperfused than in non reperfused cortex with occlusion flows below $14 \mathrm{ml} / 100$ $\mathrm{g} / \mathrm{min},(\mathrm{F}=6.51, \mathrm{p}<0.01)$. In one group of reper-

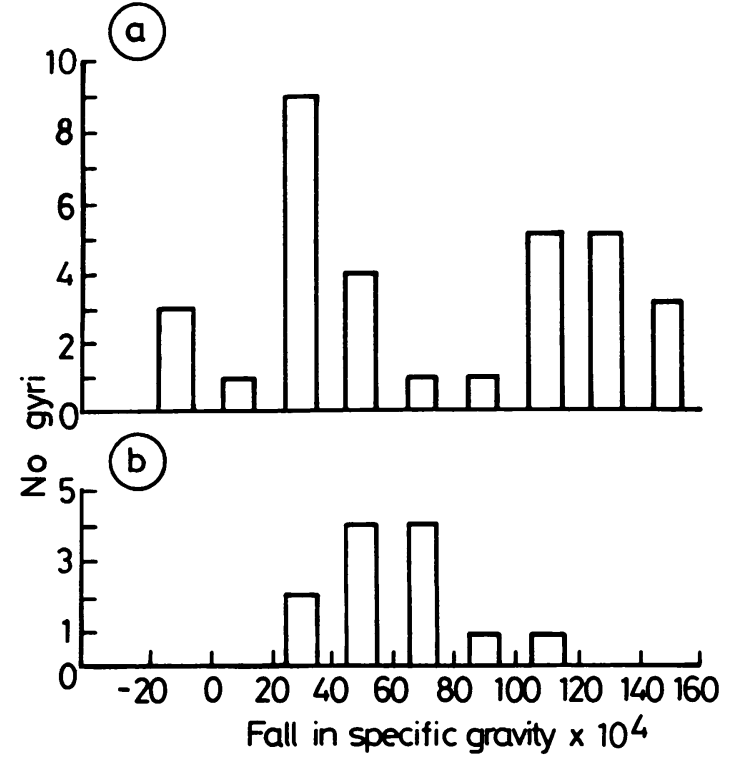

Fig 1 Distribution of reduction in specific gravity from non reperfused cortex ${ }^{2}(a)$ and reperfused cortex (b). Units are in 0.0020 specific gravity unit bins.

fused gyri with occlusion flows below $14 \mathrm{ml} / 100$ $\mathrm{g} / \mathrm{min}$ and fall in specific gravity above the mean for non reperfused cortex, ${ }^{2}$ the fall in specific gravity was significantly greater $(p<0.01)$ than that in non-reperfused cortex, whereas in a second group, with fall in specific gravity less than the mean for non reperfused cortex, the fall was significantly less ( $p<0.01)$. In this latter group the reduction in specific gravity was greater $(p<0.05)$ in cats infused with glucose (mean reduction in specific gravity $0.0037 \pm 0.0004)$ than in those receiving saline (mean reduction $0.0020 \pm 0 \cdot 0006$ ).

In vitro neurotransmitter uptake (table 3)

GABA uptake on MG was less than that in the

Table 3 (a) Cortical Specific Gravity (mean \pm SEM) and (b) In Vitro Synaptosomal GABA uptake nmol/g wet weight/min (mean $\pm S E M)$

\begin{tabular}{|c|c|c|c|c|c|c|c|}
\hline & \multirow{2}{*}{$\begin{array}{l}\text { Ischaemic } \\
M G\end{array}$} & \multicolumn{2}{|c|}{ Hemisphere } & \multirow{2}{*}{$\begin{array}{l}\text { Control } \\
M G\end{array}$} & \multicolumn{2}{|c|}{ Hemisphere } & \multirow[t]{2}{*}{ Mean } \\
\hline & & $S G$ & $E G$ & & $S G$ & $E G$ & \\
\hline $\begin{array}{l}3(a) \text { Cortical speci } \\
\text { Group } 1 \\
\text { SEM } n=10 \\
\text { Group } 2 \\
\text { SEM } n=10\end{array}$ & $\begin{array}{l}\text { gravity } \\
1 \cdot 0413 \\
0.0009 \\
1.0419 \\
0.0010\end{array}$ & $\begin{array}{l}1.0390 \\
0.0016 \\
1.0372 \\
0.0015\end{array}$ & $\begin{array}{l}1.0375 \\
0.0017 \\
1.0356 \\
0.0021\end{array}$ & $\begin{array}{l}1.0420 \\
0.0017 \\
1.0430 \\
0.0005\end{array}$ & $\begin{array}{l}1.0431 \\
0.0004 \\
1.0429 \\
0.0006\end{array}$ & $\begin{array}{l}1.0436 \\
0.0005 \\
1.0433 \\
0.0007\end{array}$ & $\begin{array}{l}1.0429 \\
0.0012 \\
1.0430 \\
0.0006\end{array}$ \\
\hline $\begin{array}{l}\text { b GABA uptake } \\
\text { Group } 1 \\
\text { SEM } \mathrm{n}=7 \\
\text { Group } 2 \\
\text { SEM } \mathrm{n}=10\end{array}$ & $\begin{array}{l}3.15 \\
0.58 \\
3.33 \\
0.57\end{array}$ & $\begin{array}{l}4 \cdot 10 \\
0 \cdot 6 \\
2 \cdot 95 \\
0 \cdot 27\end{array}$ & $\begin{array}{l}3 \cdot 88 \\
0.76 \\
3 \cdot 28 \\
0.42\end{array}$ & $\begin{array}{l}3.73 \\
0.61 \\
3.65 \\
0.61\end{array}$ & $\begin{array}{l}3.98 \\
0.47 \\
4 \cdot 20 \\
0.44\end{array}$ & $\begin{array}{l}4 \cdot 78 \\
0.63 \\
4 \cdot 12 \\
0.61\end{array}$ & $\begin{array}{l}4 \cdot 18 \\
0 \cdot 31 \\
4 \cdot 00 \\
0 \cdot 43\end{array}$ \\
\hline
\end{tabular}


homologous control hemisphere gyrus in Group 1 ( $p$ $<0.02)$; and on MG and SG $(p<0.05)$ in Group 2. Within each group there was no difference between gyri. Uptake values were lower in Group 2 than Group 1 in SG $(p<0.02)$ and EG $(p<0.05)$. By comparison with non reperfused cats, in which there is a linear relationship between GABA uptake and ischaemic flow, ${ }^{2}$ GABA uptake was higher in the reperfused infarct core, which includes EG in all experiments and SG in some (fig 2), but not significantly different in MG. There was no relationship between uptake values and CBF during reperfusion, except in penumbral gyri in which flow fell during reperfusion where GABA uptake was reduced ( $p<0 \cdot 01$, Chi squared test) (fig 3$)$.

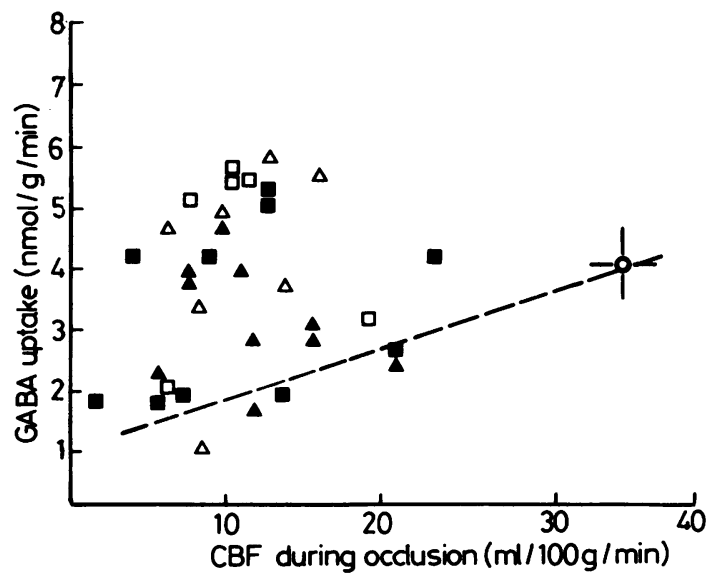

Fig 2 Relationship between in vitro synaptosomal $G A B A$ uptake and mean $C B F$ during occlusion in the infarct core (SG and EG). Gyral values for GABA uptake are higher than those predicted from non reperfused cortex, ${ }^{2}$ shown - - - Mean $\pm S E M$ for GABA uptake from the non ischaemic hemisphere and preocclusion whole hemisphere $C B F$ is shown -o-. Saline infused $S G \triangle E G \square$. Glucose infused $S G \Delta, E G \square$.

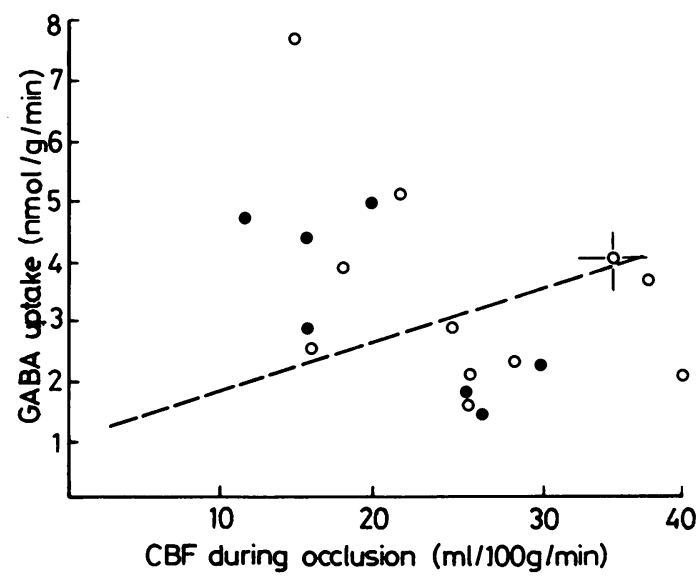

Fig 3 Relationship between in vitro GABA uptake and mean $C B F$ during occlusion in the infarct penumbra (MG). Values for non reperfused cortex as in fig 2. Saline infused $M G$ O. Glucose infused $M G O$.

Pial surface potassium activity (Kp) (table 4)

The changes in Kp seen following occlusion have already been reported.' Superimposed transcriptions of $\mathrm{Kp}$ electrode outputs $(\mathrm{mV})$ are shown in fig $4 \mathrm{a}$, (occlusion) and fig $4 \mathrm{~b}$ (reperfusion). In one experiment in Group 2 the rise in $\mathrm{Kp}$ was due to a fall in mean arterial pressure during ischaemia. Values of $\mathrm{Kp}$ on MG were significantly higher in Group 2 at the end of the occlusion and this difference was maintained throughout reperfusion $(p=0.02$, excluding data from hypotensive animal).

\section{Discussion}

Considerable evidence exists to suggest that hyperglycaemia, by increasing brain lactic acidosis, may be harmful during cerebral ischaemia. Most of this evidence is experimental, with induction of ischaemia after hyperglycaemia has been estab-

Table 4 Pial surface potassium activity mmol/l (mean $\pm S E M$ )

\begin{tabular}{|c|c|c|c|c|c|c|}
\hline & \multirow[t]{3}{*}{ Preocclusion } & \multicolumn{4}{|l|}{ Occlusion } & \multirow{3}{*}{$\frac{\text { Reperfusion }}{\text { Terminal }}$} \\
\hline & & \multirow[t]{2}{*}{ Initial } & \multirow[t]{2}{*}{ Terminal } & \multicolumn{2}{|c|}{ Rise in $K p$} & \\
\hline & & & & transient & sustained & \\
\hline \multirow{4}{*}{$\begin{array}{c}\text { Group 1 } \\
\text { Marginal } \\
n=6 \\
\text { Suprasylvian } \\
n=7 \\
\text { Group 2 } \\
\text { Marginal } \\
n=8 \\
\text { Suprasylvian } \\
n=7\end{array}$} & $2 \cdot 88 \pm 0.18$ & $7 \cdot 05 \pm 2.0$ & $4.08 \pm 0.52$ & 5 & 0 & $3 \cdot 18 \pm 0.34$ \\
\hline & $3 \cdot 30 \pm 0 \cdot 29$ & $33.90 \pm 5.49$ & $20 \cdot 2 \pm 3.75$ & 1 & 6 & $3.78 \pm 0.25$ \\
\hline & $3.00 \pm 0.12$ & $7 \cdot 82 \pm 1 \cdot 31$ & $11.7 \pm 3.71$ & 5 & 3 & $6.68 \pm 1.99$ \\
\hline & $2 \cdot 90 \pm 0.20$ & $15 \cdot 0 \pm 4.79$ & $13.6 \pm 3.93$ & 1 & 6 & $8.0 \pm 3.93$ \\
\hline
\end{tabular}




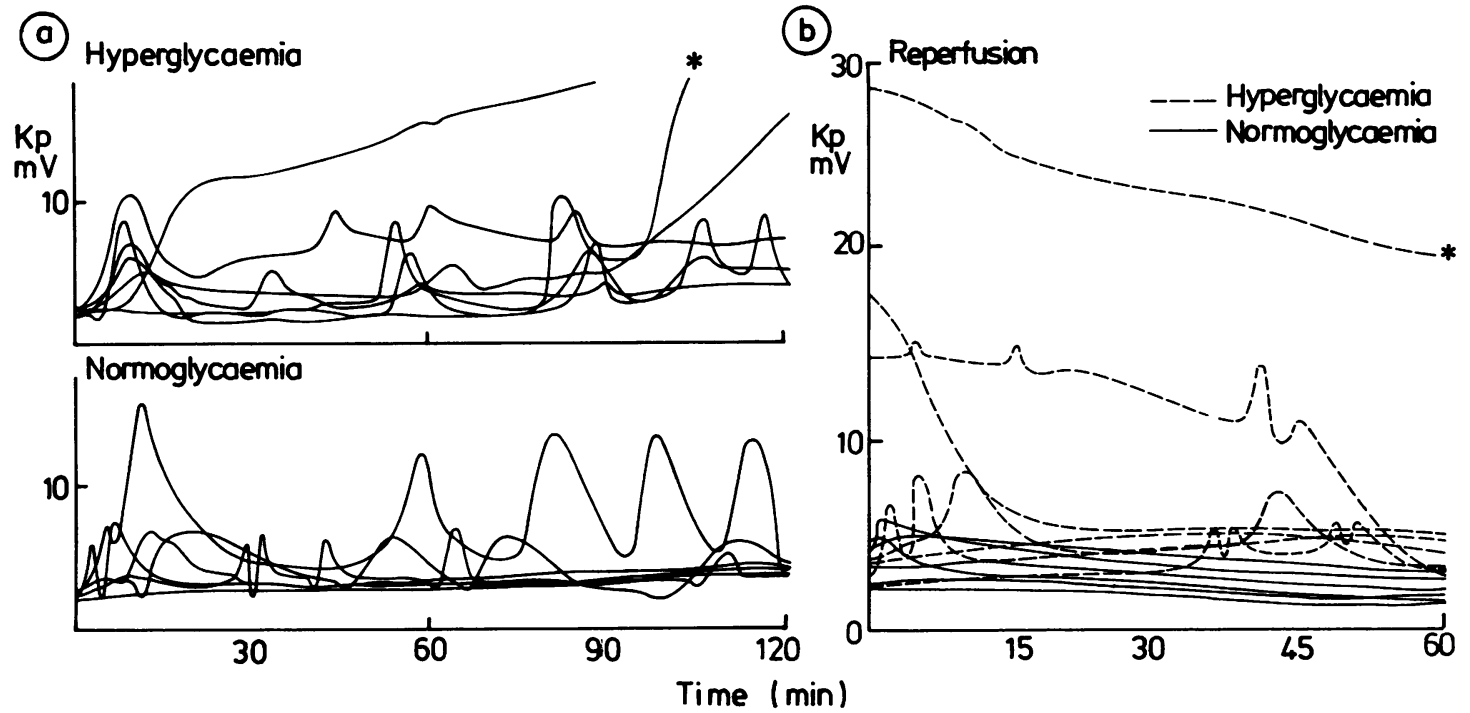

Fig 4 Superimposed transcriptions of Kp electrode outputs $(m V)$ from $M G$ in saline infused and glucose infused cats, (a) during occlusion and (b) during reperfusion. The single experiment in which there was a sustained rise in Kp due to hypotension is shown $(*)$. The difference in $K p$ at the end of reperfusion was significant $(p<0.02)$ regardless of the inclusion of this experiment in the data.

lished, that is after the brain has been preloaded with glucose. ${ }^{4-15}$ In man, however, when hyperglycaemia is seen in the absence of pre existing diabetes, it is presumed to develop after onset of stroke. Diabetics, ${ }^{16}$ and individuals with mild hyperglycaemia ${ }^{17}$ have a greater risk of cerebral vascular disease than normoglycaemic individuals, and Pulsinelli et al ${ }^{18}$ confirmed in a comparative study that diabetics did worse clinically after ischaemic stroke. In a recent study in Newcastle $95 \%$ patients developing neurological deterioration after subarachnoid hemorrhage were found to have an elevated fasting blood sugar on at least one occasion. ${ }^{19}$ This study was designed to investigate whether a pattern of hyperglycaemia resembling that in man might worsen the effects of the ischaemia. Since deterioration may follow reperfusion, and Myers' results were obtained in a reperfusion model ${ }^{10-12}$ we investigated the effects of reperfusion following both saline and glucose loading after the onset of ischaemia. In the light of recent observations ${ }^{20}$ suggesting that blood glucose levels above a value of $100 \mathrm{mg} \%(5.5 \mathrm{mmol} / \mathrm{l})$ may be detrimental in stroke in man the present study should be regarded as a comparison between the effects of moderate and severe hyperglycaemia. Blood glucose levels during preparation and in the "normoglycaemic" group were mildly elevated presumably as a result of stress, but were comparable with those measured in animals subject to occlusion alone. ${ }^{21}$

\section{Local blood flow}

The pattern of blood flow during the ischaemia closely resembled that seen in animals subject to occlusion alone. ${ }^{1}$ Patterns of CBF were similar in both groups of animals other than on MG where flow fell during reperfusion in glucose-infused cats. The length and depth of the ischaemia are factors thought to influence the pattern of recovery of flow after focal and global ischaemia. Steen $e t a^{22}$ found reperfusion CBF after incomplete ischaemia to be slightly higher than after complete ischaemia and related it to the length of the ischaemia. Ginsberg $e t$ $a l^{23}$ found that after longer periods of global complete ischaemia inhomogeneities of flow with zones of severe persistent ischaemia appeared suggesting that full functional recovery was unlikely. In focal cerebral ischaemia Traupe $e t \boldsymbol{a l}^{3}$ found that early postischaemic hypoperfusion was related to the length of the ischaemia, and even when CBF returned to normal hypoperfusion developed after a further hour of recirculation. Such degrees of hypoperfusion were not seen in this study, though diversion of blood into a vasodilated central ischaemic territory may have accounted for the fall in $\mathrm{CBF}$ on MG in glucose infused cats.

\section{Cortical specific gravity}

Reduction in cortical specific gravity occurred below flows of $14 \mathrm{ml} / 100 \mathrm{~g} / \mathrm{min}$, that is, in the infarct core but not in the penumbra. This apparent CBF 
threshold is lower than that seen in the baboon, ${ }^{24}$ though comparable with that found previously by ourselves $^{2}$ and by Schuier and Hossmann in the cat. ${ }^{25}$ Reperfusion had no effect on the threshold for oedema formation, but below the threshold there were two distinct groups of gyri, one with more and one with less water than would have been predicted on the basis of results from animals which had not been reperfused. There are at least two possible explanations for this. First, ischaemic cortex is known to contain more albumin, ${ }^{26}$ and extravasated protein adds to brain solids, so tending to preserve an apparently normal specific gravity despite water accumulation. ${ }^{27}$ Alternatively, in certain areas reperfusion may allow preserved or at least only partially damaged water clearance mechanisms to operate, whereas in others greater damage may occur. This may be the case in man where, after ischaemic stroke, neurological deterioration occurring after early improvement is not infrequently due to oedema. In these experiments reduction in specific gravity did not appear to relate to flow during reperfusion, integrated reflow, potassium activity or recovery of neurotransmitter uptake.

\section{GABA uptake}

Potential errors in the interpretation of GABA uptake values have been reviewed previously. ${ }^{2}$ In cats subject to ischaemia without reperfusion there is a topographical gradient of loss of GABA uptake which may represent an effect of ischaemia on the synaptic compartment, either through changes in synaptosomal glycolysis, or through damage to the uptake site. ${ }^{2}$ In the present study, on reperfusion (as opposed to the in vitro reprovision of substrate) there is recovery of uptake mechanisms within areas which form the infarct core, though values from glucose infused cats were lower than those from saline infused cats. In the penumbra, uptake values did not differ significantly from values found in the marginal gyrus in non reperfused cats, ${ }^{2}$ though lower values were obtained from gyri in which flow had fallen during reperfusion.

\section{Pial surface potassium activity}

In saline infused cats $\mathrm{Kp}$ tended to recover to baseline values during reperfusion. In glucose infused cats $\mathrm{Kp}$ values in the penumbra at the end of occlusion were higher than those seen in saline infused cats. This difference persisted during reperfusion, and may have been related to the fall in CBF seen on MG during reperfusion.

\section{Hyperglycaemia and the evolution of a cerebral infarct}

The evidence found in these experiments for an adverse effect of hyperglycaemia on the evolution of a cerebral infarct may be summarised as follows:

1 A fall in CBF during reperfusion of the marginal gyrus in glucose-infused cats.

2 In cortex subject to core values of blood flow and with an overall fall in specific gravity less than that occurring in non reperfused cortex, reduction in specific gravity was greater in glucose-infused cats.

3 GABA uptake in reperfused core territories was less in glucose-infused than in saline-infused cats.

4 Recovery of pial surface potassium activity during reperfusion was less complete in glucose-infused than in saline-infused cats. In some instances the differences between groups, although significant, were not great, and in the light of the findings in man it is possible that a comparison of plasma glucose values in the range of 3-4 $\mathrm{mmol} / 1$ (54-72 $\mathrm{mg} \%$ ) with those in the range recorded in the saline-infused cats in the present studies (8-10 mmol/l, 144-188 $\mathrm{mg} \%$ ) might provide further evidence of an adverse effect of increasing blood sugar.

\section{Acidosis and the penumbra}

It is still unclear whether flow reduction in penumbral areas as defined by ECoG suppression reflects ischaemia, or whether it is due to local diaschisis resulting either from damage to a small pool of functionally critical neurones or from loss of collateral functional input from the infarct core. The presentfindings from the reperfused cortex suggest greater damage in the penumbra in association with marked $\frac{0}{5}$ hyperglycaemia. This apparent vulnerability of penumbra to an elevated blood sugar level suggests that such zones are ischaemic rather than simply the site of diaschisis. This suggestion is supported by our data from surface $\mathrm{pH}$ selective electrodes placed on the marginal gyrus, which indicate that acidosis is an early change in progressive ischaemia. ${ }^{28}$

\section{Conclusion}

In conclusion, the present results suggest that changes both in the core and the penumbra of an ischaemic territory may be influenced adversely by marked hyperglycaemia, to a degree which can affect recovery during reperfusion: this is most probably due to increased acidosis. In the context of conditions associated in man with areas of mild to moderate focal ischaemia such as occlusive stroke or vasospasm following aneurysmal subarachnoid haemorrhage, our findings suggest that the effects of a given degree of mild ischaemia may be amplified by hyperglycaemia, and that the relationship of hyperglycaemia with the severity of stroke may represent a cause as well as an effect. A metabolic vicious circle may thus develop in which the hyperglycaemic component of the stress response to 
stroke serves in turn to increase the extents both of swelling and of definitive neuronal loss. The implication that restriction of glucose availability might improve the outcome from ischaemic stroke is under investigation; recent findings in this laboratory suggest partial protection of mitochondrial respiration in cerebral ischaemia by induction of mild hypoglycaemia (3-4 mmol/l). . $^{29}$

We thank the British Heart Foundation, the Medical Research Council and Newcastle Health Authority for financial support. We are very grateful to Mrs B Orrin for technical help.

\section{References}

' Strong AJ, Venables GS, Gibson G. The cortical ischaemic penumbra associated with occlusion of the middle cerebral artery in the cat. 1: Topography of changes in blood flow, potassium ion activity and EEG. J Cereb Blood Flow Metabol 1983;3:86-96.

2 Strong AJ, Tomlinson BE, Venables GS, Gibson G, Hardy JA. The cortical ischaemic penumbra associated with occlusion of the middle cerebral artery in the cat. 2: Studies of histopathology, water content and in vitro neurotransmitter uptake. J Cereb Blood Flow Metabol 1983;3:97-108.

${ }^{3}$ Traupe H, Kruse E, Heiss WD. Reperfusion of focal ischaemia of varying duration: post ischaemic hyper and hypo perfusion. Stroke 1982;13:615-22.

${ }^{4}$ Siesjo BK. Cerebral circulation and metabolism. J Neurosurg 1984;60:883-908.

${ }^{5}$ Symon L, Pasztor E, Branston NM. The distribution and density of reduced cerebral blood flow following acute middle cerebral artery occlusion: An experimental study by the technique of hydrogen clearance. Stroke 1974;5:355-64.

- Rehncrona S, Rosen I, Siesjo BK. Excessive cellular acidosis: an important mechanism of neuronal damage in the brain. Acta Physiol Scand 1980;110:435-7.

${ }^{7}$ Eklof B, Siesjo BK. The effect of bilateral carotid artery ligation upon acid base parameters and substrate levels in the rat brain. Acta Physiol Scand 1972;86: 528-38.

${ }^{8}$ Salford LG, Siesjo BK. The influence of arterial hypoxia and unilateral carotid artery occlusion upon regional blood flow and metabolism in the rat brain. Acta Physiol Scand 1974;92:130-41.

${ }^{9}$ Ljunggren B, Norberg K, Siesjo BK. Influence of tissue acidosis upon restitution of brain energy metabolism following total ischaemia. Brain Res 1974;77:173-86.

${ }^{10}$ Myers RE. Anoxic brain pathology and blood glucose. Neurology (Minneap) 1976;26:345. (Abstr)

"Myers RE, Yamaguchi S. Nervous system effects of cardiac arrest in monkeys. Arch Neurol 1977;34:65-74.

12 Myers RE. Lactic acid accumulation as a cause of brain edema and cerebral necrosis resulting from oxygen deprivation. In: Korobkin R, Guilleminault C, eds. Advances in Perinatal Neurology. New York: Spectrum Publications, 1979;85-114.

${ }^{13}$ Hansen AJ. The extracellular potassium concentration in brain cortex following ischaemia in hypo and hyperglycaemic rats. Acta Physiol Scand 1978;102:324-9.

${ }^{14}$ Gjedde A, Siemkowicz E. Effect of glucose pretreatment on cerebral metabolic recovery after ischaemia. Ann Neurol 1978;4:166-7.

is Siemkowicz E, Hansen AJ. Brain extracellular ion composition and EEG activity following 10 minutes ischaemia in normo and hyperglycaemic rats. Stroke 1981;12:236-40.

${ }^{16}$ Palumbo PJ, Elveback LR, Whisnant JP. Neurological complications of diabetes mellitus; transient ischaemic attacks, stroke and peripheral neuropathy. In: Schoenberg BS, ed. Neurological Epidemiology. New York: Raven Press, 1978;593-9.

${ }^{17}$ Riddle MC, Hart J. Hyperglycaemia, recognised and unrecognised as a risk factor for stroke and transient ischaemic attacks. Stroke 1982;13:356-9.

${ }^{18}$ Pulsinelli W, Waldman S, Sigsbee B, Rawlinson D, Plum F. Experimental hyperglycaemia and diabetes mellitus worsen stroke outcome. In: Betz E, Grote J, Heuser D, eds. Pathophysiology and Pharmacology of Cerebrovascular Disease. Baden Baden: Gerhard Witzstrock, 1980;196-9.

${ }^{14}$ Sastry-Kolluri KVR. Haematological and biochemical changes in aneurysmal subarachnoid haemorrhage. MSc Thesis. University of Newcastle, 1982.

${ }^{20}$ Mohr JP. Approaches to pathophysiology of stroke through NINCDS data bank. In: Plum F, ed. 14th Princeton Stroke Conference. New York: Raven Press, 1984. (In Press)

21 Venables GS. Experimental focal cerebral ischaemia in the cat. DM. Thesis. University of Oxford, 1983.

${ }^{22}$ Steen PA, Michenfelder JD, Milde JH. Incomplete versus complete cerebral ischaemia. Improved outcome with a minimal blood flow. Ann Neurol 1979;6:389 98.

${ }^{23}$ Ginsberg MD, Budd WW, Welsh FA. Diffuse cerebral ischaemia in the cat. I Local blood flow during severe ischemia and recirculation. Ann Neurol 1978;3:48292.

24 Symon L, Branston NM, Chikovani O. Ischaemic brain edema following middle cerebral artery occlusion in baboons: Relationship between regional cerebral water content and blood flow at 1-2 hours. Stroke 1979; 10: 184-91.

${ }^{25}$ Schuier FJ, Hossmann KA. Experimental brain infarcts in cats. II Ischaemic brain edema. Stroke 1980;11:593-601.

${ }^{26}$ Bowen DM, Goodhardt MJ, Strong AJ, et al. Biochemical indices of brain structure, function and 'hypoxia' in cortex from baboons with middle cerebral artery occlusion. Brain Res 1976;117:503-7.

${ }^{27}$ Marmarou A, Tanaka K, Shulman K. An improved gravimetric measure of cerebral oedema. J Neurosurg 1982;56:246-53.

${ }^{28}$ Gibson G, Miller SA, Venables GS, Strong AJ. Evidence of acidosis in the ischaemic penumbra. $J$ Cereb Blood Flow Metabol 1983;Suppl 1:S401-S402.

${ }^{29}$ Strong AJ, Miller SA, West IC. Protection of respiration of a crude mitochondrial fraction in cerebral ischaemia by control of blood glucose. J Neurol Neurosurg Psychiatry (In Press). 